\title{
F-BAR family proteins, emerging regulators for cell membrane dynamic changes-from structure to human diseases
}

Suxuan Liu ${ }^{1,2}$, Xinyu Xiong ${ }^{2}$, Xianxian Zhao ${ }^{1 *}$, Xiaofeng Yang ${ }^{2,3,4^{*}}$ and Hong Wang ${ }^{1,2,3,4^{*}}$

\begin{abstract}
Eukaryotic cell membrane dynamics change in curvature during physiological and pathological processes. In the past ten years, a novel protein family, Fes/CIP4 homology-Bin/Amphiphysin/Rvs (F-BAR) domain proteins, has been identified to be the most important coordinators in membrane curvature regulation. The F-BAR domain family is a member of the Bin/Amphiphysin/Rvs (BAR) domain superfamily that is associated with dynamic changes in cell membrane. However, the molecular basis in membrane structure regulation and the biological functions of F-BAR protein are unclear. The pathophysiological role of F-BAR protein is unknown. This review summarizes the current understanding of structure and function in the BAR domain superfamily, classifies F-BAR family proteins into nine subfamilies based on domain structure, and characterizes F-BAR protein structure, domain interaction, and functional relevance. In general, F-BAR protein binds to cell membrane via F-BAR domain association with membrane phospholipids and initiates membrane curvature and scission via Src homology-3 (SH3) domain interaction with its partner proteins. This process causes membrane dynamic changes and leads to seven important cellular biological functions, which include endocytosis, phagocytosis, filopodium, lamellipodium, cytokinesis, adhesion, and podosome formation, via distinct signaling pathways determined by specific domain-binding partners. These cellular functions play important roles in many physiological and pathophysiological processes. We further summarize F-BAR protein expression and mutation changes observed in various diseases and developmental disorders. Considering the structure feature and functional implication of F-BAR proteins, we anticipate that F-BAR proteins modulate physiological and pathophysiological processes via transferring extracellular materials, regulating cell trafficking and mobility, presenting antigens, mediating extracellular matrix degradation, and transmitting signaling for cell proliferation.
\end{abstract}

Keywords: F-BAR proteins, Membrane dynamics, Cellular functions, Pathophysiology

\section{Introduction}

Cell membrane curvature is a micro morphological change involved in many important cellular processes including endocytosis, phagocytosis, exocytosis, angiogenisis, and migration. The ability of cell membrane to achieve these dynamics is heavily determined by the collaboration between actin cytoskeleton and membrane-interacting proteins. Recently, a group of proteins named Fes/CIP4 homology-Bin/

\footnotetext{
*Correspondence: xianxianz2010@163.com; xfyang@temple.edu; hongw@temple.edu

'Department of Cardiology, Changhai Hospital, Second Military Medical University, Shanghai 200433, China

${ }^{2}$ Center for Metabolic Disease Research, Department of Pharmacology, Temple University School of Medicine, Philadelphia, PA 19140, USA Full list of author information is available at the end of the article
}

Amphiphysin/Rvs (F-BAR) domain family has emerged as the critical coordinators that regulate membrane curvature [1]. F-BAR proteins are membrane-associated proteins and regulate membrane curvature via binding to cell membrane phospholipids. F-BAR domain family is a member of the Bin/Amphiphysin/Rvs (BAR) domain superfamily which also includes the N-terminal amphipathic helix BAR (N-BAR) domain family and inverse BAR (I-BAR) domain family.

Recently, research has started to reveal potential functions for F-BAR proteins. However, the structures and functional diversities of the mammalian F-BAR family have not been elucidated. The mechanisms underlying F-BAR proteins regulating cell membrane dynamic changes and the 
pathophysiological roles of F-BAR proteins in human diseases are not clear. We present here a comprehensive analysis of the current understanding for structure, signaling, biological function, and pathophysiological association of the mammalian F-BAR family, and its association with diseases and development disorders in human and experimental animal models.

\section{BAR protein superfamily}

The F-BAR protein was originally identified in a yeast two-hybrid system screen as CDC42-interacting protein 4. (CIP4) [2]. As indicated in Figure 1A, the N-terminal region of CIP4 was found to be highly conserved in several other proteins, such as tyrosine kinase FES and FES related (FER), thus termed as FES/CIP4 homology $(\mathrm{FCH})$ domain. The FCH domain is next to a coiled-coil domain similar to BAR domain and constitutes a functional unit that together are termed as F-BAR domain. The F-BAR domain is evolutionarily conserved within eukaryotes and can bind to the negatively charged membrane phospholipids in lipid membranes to bridge the cytoskeleton and cell membrane.

The F-BAR family belongs to the BAR superfamily, which also includes N-BAR and I-BAR families and possesses a similar N-terminal BAR domain. At the C-terminal region, the BAR superfamily contains various combinations of different domains, such as Src homology3 (SH3) domain, Src homology-2 (SH2) domain, tyrosine kinase domain, Rho GTPase-activating protein (RhoGAP) domain, WW domain, protein kinase C-related kinase homology region 1 (HR1) domain, and $\mu$-homology domain $(\mu \mathrm{HD})$ (Figure 1A-C). Particularly, the name "WW" domain refers to two strictly conserved tryptophans (W) in this domain. Based on literature information on domain characterization studies, we classified mammalian F-BAR family into nine subfamilies: CIP4, FCH only (FCHO), Slit-Robo GTPase-activating protein (srGAP), protein kinase $\mathrm{C}$ and casein kinase 2 substrates in neurons (PACSIN), proline-serine-threonine phosphatase-interacting protein (PSTPIP), FCH and double SH3 domain proteins (FCHSD), FES/FER, nitric oxide synthase traffic inducer (NOSTRIN), and growth arrest-specific 7 (GAS7) subfamilies [3-7].

The F-BAR, N-BAR, and I-BAR domain proteins can form a homodimer to generate a crescent-shaped structure with a family-specific radius of curvature [6] (Figure 1D). The distinctive feature of F-BAR domains is to bind to the membrane and form a shallow degree of invagination/concavity micro membrane morphologic change, with an arc depth $\sim 3$-fold smaller than those of N-BAR domains. The I-BAR domains are associated with a protrusion/convexity in the micro membrane morphologic change. Accordingly, F-BAR proteins and N-BAR proteins are normally involved in the invagination of membrane leading to endocytosis and phagocytosis [8]. I-BAR proteins are associated with the outwardly curved membranes for the formation of filopodium, lamellipodium, and angiogenesis [9].

Recently, F-BAR proteins have been identified as the novel and important coordinators that regulate not only endocytosis and phagocytosis but also filopodium, lamellipodium, cytokinesis, adhesion, and podosome formation. To fully understand the cellular functions of F-BAR protein family, it is important to analyze molecular basis, binding partners, and structure-function relationships of F-BAR proteins, and their functional implication.

\section{F-BAR proteins and membrane dynamics}

As described above, F-BAR protein binds to phospholipids through the N-terminal F-BAR domain and bridges the membrane with cytoskeleton. However, we could not ignore the other domains of F-BAR protein that determine their specific function. We analyzed the structure of F-BAR proteins and proposed a modified characterization model for mammalian F-BAR family, which includes CIP4, FCHO, srGAP, PACSIN, PSTPIP, FCHSD, FES/FER, NOSTRIN, and GAS7 subfamilies.

Most F-BAR proteins contain at least one C-terminal SH3 domain. The SH3 domain is an evolutionarily conserved protein-protein interaction domain of 50-60 amino acids. In general, F-BAR proteins bind to cell membrane via F-BAR domain association with membrane phospholipids (Figure 2). Through its SH3 domain, F-BAR proteins interact with proline-rich proteins like the Wiskott-Aldrich syndrome protein (WASP), neural (N)-WASP, and WASP family verproline-homologous protein (WAVE), which leads to WASP/N-WASP protein conformation change from a closed autoinhibitory conformation to an opened structure. The opened WASP/N-WASP protein exposes its C-terminal verprolin, cofilin, acidic (VCA) and CDC42Rac interactive binding (CRIB) domains, which is activated and binds to actin-related protein 2/3 (Arp2/3) and G-actin, leading to the nucleation of filamentous actin (F-actin) and polymerization of actin (Figure 2) [10]. Actin polymerization causes various membrane curvatures, including endocytosis, phagocytosis, filopodium, and podosome. Some F-BAR proteins can further bind to the GTPase dynamin via SH3 domain, generate direct cometlike force by F-actin to push the membrane, and initiate the scission of vesicle [11].

\section{Structure and cellular functions of F-BAR family}

We further analyzed the domain structures, interactions, and specific binding partners of nine F-BAR protein subfamilies (Figure 3A), summarized the cellular functions carried out by different F-BAR protein domain-binding partner interactions (Figure $3 \mathrm{~B}$ ), described the procedure of F-BAR protein-mediated cellular function (Figure 4), and discussed the details below. 
A F-BAR family

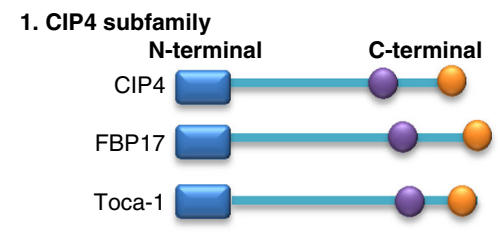

\section{FCHO subfamily}

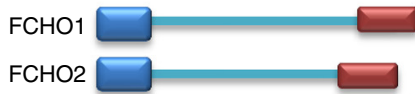

3. SrGAP subfamily

SrGAP1-4

\section{PACSIN subfamily}

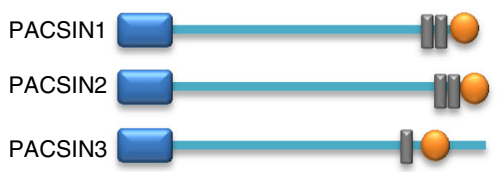

B N-BAR family

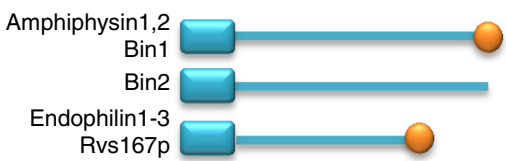

5. PSTPIP subfamily

$\mathrm{N}$-terminal C-terminal

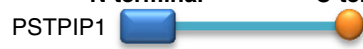

PSTPIP2

6. FCHSD subfamily

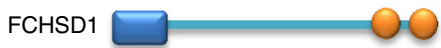

FCHSD2 $\square \quad \square$

(Carom)

7. FES/FER subfamily

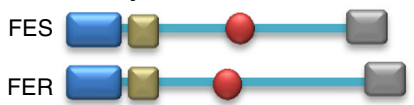

8. NOSTRIN subfamily

NOSTRIN

9. GAS7 subfamily

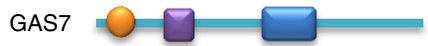

C I-BAR family

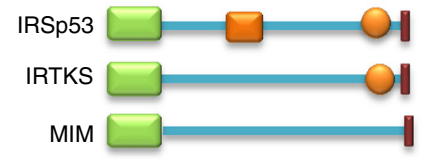

D Membrane curvature forms caused by BAR domain proteins

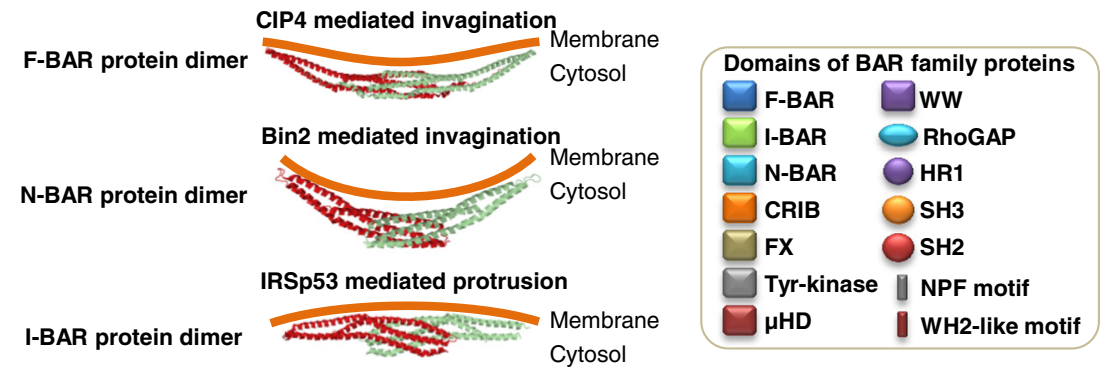

Figure 1 F-BAR, N-BAR and I-BAR family domain structure and membrane curvature models. BAR domain superfamily consists of three families based on distinct domain structures of F-BAR, N-BAR, and I-BAR. Bar domain proteins can form homodimer which binds to cell membrane leading to membrane curvature. (A) Domain structures of F-BAR family. F-BAR family has nine subfamilies determined by the specific domain combination. (B) Domain structures of N-BAR family. (C) Domain structures of I-BAR family. (D) Membrane curvature forms caused by BAR domain proteins. F-BAR, N-BAR, and I-BAR proteins bind to cell membrane and lead to different forms of curvature changes. Domain information is based on previous publications $[1,3,4,7,8]$. Crystal structure (a red monomer and a green monomer forming a dimer) is generated by using Protein Data Bank (PDB, http://www.rcsb.org/pdb/home/home.do). Abbreviations: BAR, Bin/Amphiphysin/Rvs; CRIB, CDC42-Rac interactive binding; F-BAR, Fes/CIP4 homology-BAR; FX, F-BAR extension; HR1, Protein kinase C-related kinase homology region 1; I-BAR, Inverse BAR; N-BAR, N-terminal amphipathic helix BAR; NPF, Asparagine proline phenylalanine; RhoGAP, Rho GTPase-activating protein; SH2, Src homology-2; SH3, Src homology-3; WH2, WASP homology 2; Tyr-kinase, Tyrosine kinase; $\mu \mathrm{HD}$, $\mu$-homology domain. Symbols listed in the framed box indicate representative domains.

\section{CIP4 subfamily}

CIP4 subfamily is a member of F-BAR domain proteins containing an F-BAR domain at the N-terminal, an HR1 domain in the middle, and a SH3 domain at the C-terminal. There are three CIP4-like proteins, CIP4, formin-binding protein 17 (FBP17), and transactivator of cytoskeletal assembly-1 (Toca-1).

CIP4 recruits WASP and GTPase dynamin via SH3 domain to participate in the initiation and scission of clathrin-dependent endocytic vesicle [12]. CIP4 has also been reported to be involved in endosomal trafficking. It is reported that the localization of CIP4 to endosomes was mediated in part via the curved phosphoinositidebinding face of the CIP4 F-BAR domain, that CIP4 is localized to early endosomes, and that its downregulation led to elevated epidermal growth factor receptor trafficking and cell cycle progress [13]. CIP4 is also found to inhibit neurite formation by producing lamellipodium 


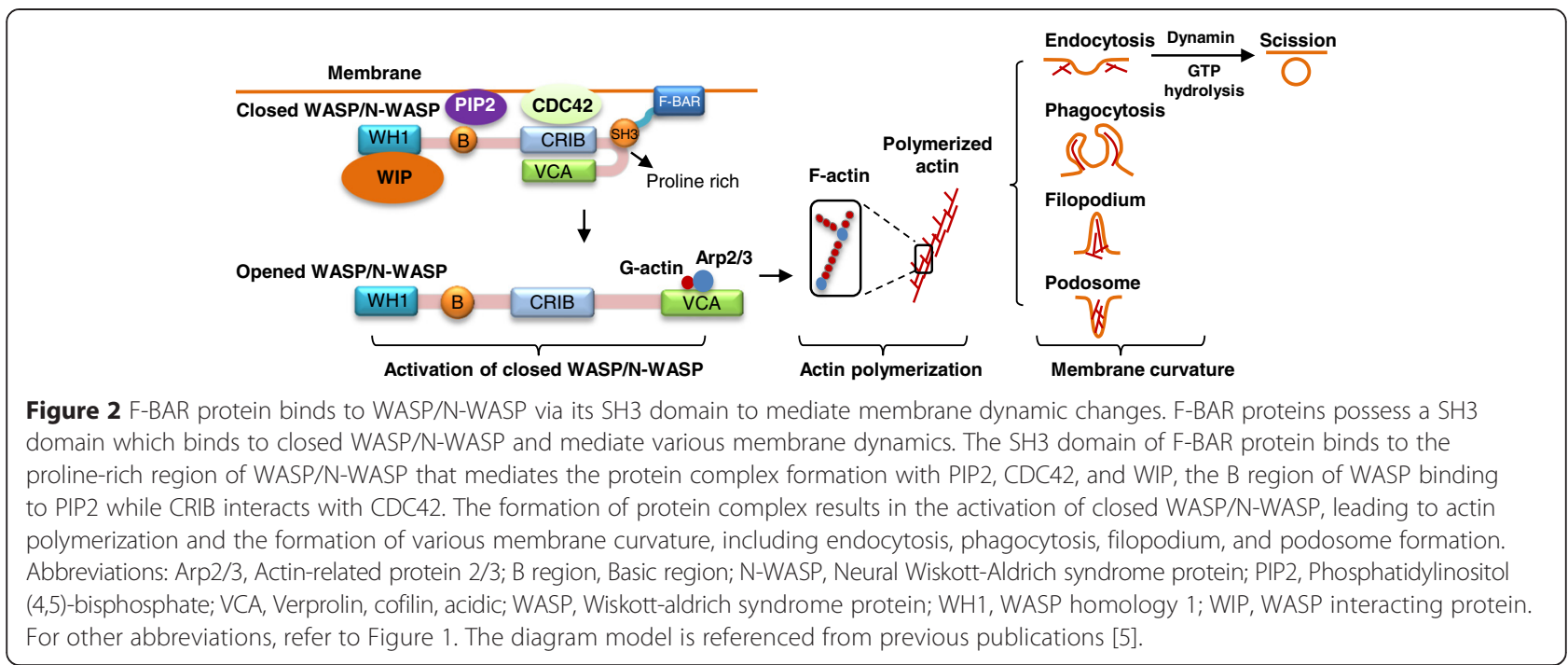

in mouse cortical neurons, and it is dependent on the F-BAR and SH3 domain and its ability to multimerize [14]. Lamellipodium and Filopodium are dynamic actinbased membrane structures. Filopodium is necessary for neurite formation while lamellipodium may inhibit neurite formation $[15,16]$.

FBP17, similar to CIP4, mediates the endocytosis of clathrin-dependent vesicle by recruiting WASP and dynamin for the vesicle initiation and scission [8]. FBP17 is associated with phagocytosis and podosomes in macrophages via recruiting WASP and dynamin-2 to membrane; the latter one is the ubiquitously expressed dynamin isoform [17]. The recruitment is the common molecular step required for the formation of podosomes and phagocytic cups.

Toca-1 has been shown to induce both endocytic vesicle and filopodium depending on CDC42/N-WASP-mediated actin polymerization [18]. Toca-1 is involved in endocytosis and filopodium and facilitates the coordination of membrane trafficking and morphology pathways. The induction of filopodium and neurite formation by Toca- 1 can be inhibited by blockers of endocytosis. However, the potential mechanism of Toca-1 involved in filopodial formation and endocytic vesicle remains unclear.

\section{FCHO subfamily}

FCHO include two members, $\mathrm{FCHO} 1$ and $\mathrm{FCHO} 2$, containing an $\mathrm{N}$-terminal F-BAR and C-terminal $\mu \mathrm{HD}$ domain. FCHOs bind to the membrane via F-BAR domain and recruit the binding partners, Eps15 and intersectin, via its $\mu \mathrm{HD}$ domain to initiate a clathrin-dependent vesicle. FCHOs accumulate at the membrane before clathrin assembly and dissociate from the vesicle before it departs from the membrane (Figure 4). Both FCHO1 and FCHO2 are ubiquitously expressed. The expression of FCHOs was related with vesicle number and increased synaptic vesicle marker recycling. RNA interference (RNAi)-induced FCHO1 and FCHO2 reduction blocks endocytosis at early step [19].

\section{SrGAP subfamily}

srGAP subfamily includes four members, srGAP1, srGAP2, srGAP3, and srGAP4, and are potentially involved in neuronal migration and angiogenesis. srGAP contains an N-terminal F-BAR domain, a central RhoGAP domain, and a C-terminal SH3 domain. SH3 domain binds to WASP in srGAP1, N-WASP in srGAP2, and WAVE1 in srGAP3 [20,21]. srGAP1-3 induce filopodium formation in mouse Neuro2a cells, similar to I-BAR protein IRSp53induced membrane protrusion [22]. Therefore, srGAP subfamily is considered as "inverse F-BAR" (IF-BAR) to mediate membrane protrusion. Recently, srGAP4 has been reported to inhibit the outgrowth of hippocampal axons, and its F-BAR domain appeared to be more important for spatially localizing srGAP4 to axon growth cones [23]. It is suggested that hat srGAP1 binds to CDC42 and RhoA, that srGAP2 and srGAP3 interact with Rac1, and that srGAP4 binds to both CDC42 and Rac1 via RhoGAP domain to promote GTP hydrolysis [21,20,23].

\section{PACSIN subfamily}

PACSIN, also known as syndapins, have three isoforms including PACSIN1, PACSIN2, and PACSIN3, all containing an $\mathrm{N}$-terminal F-BAR domain, a C-terminal SH3 domain, and NPF motif. PACSIN are associated with WASP or dynamin via their SH3 domain, leading to WASP-dependent activation, dynamin-dependent scission, and eventually endocytosis [24]. The F-BAR domains of PACSIN1 and PACSIN2 also have a hydrophobic insertion loop, as found to promote endocytic vesicle scission. Overexpression of F-BAR domain of PACSIN2 


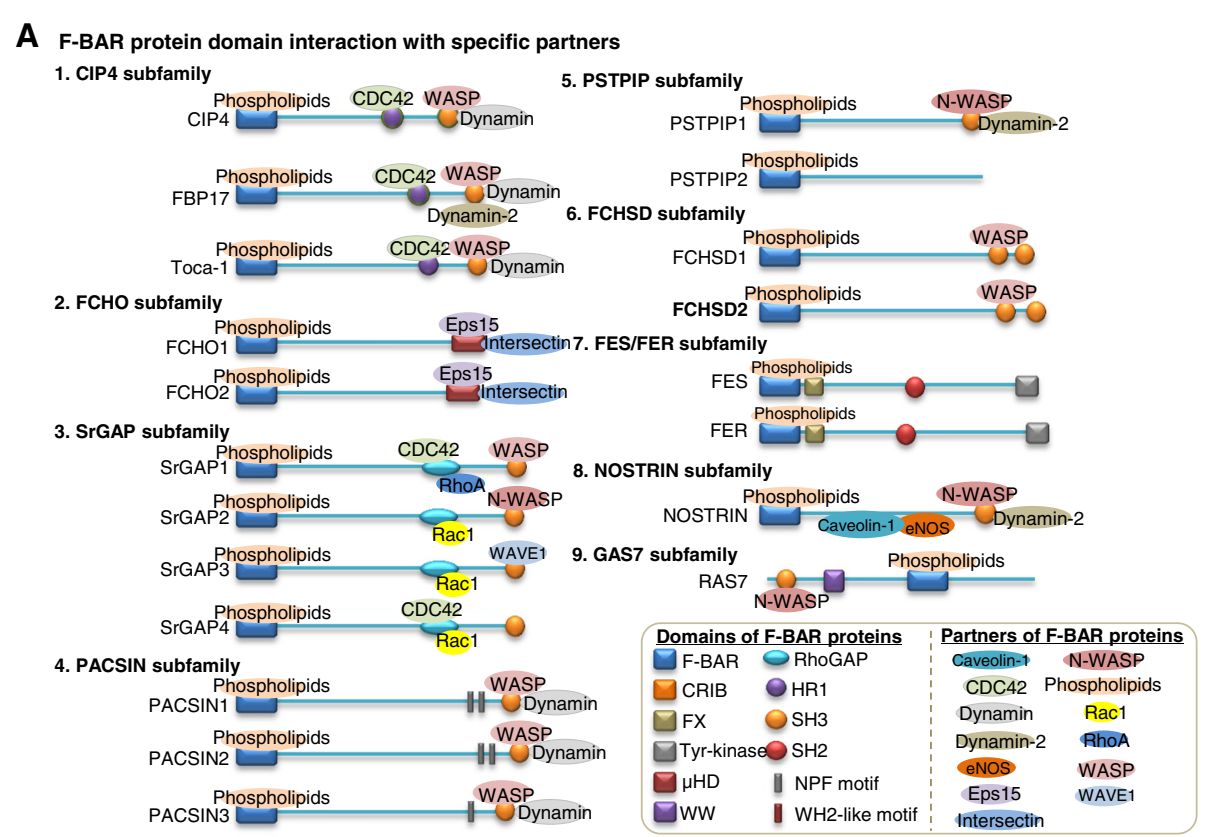

B Cellular functions carried out by F-BAR protein domain-binding partner interaction

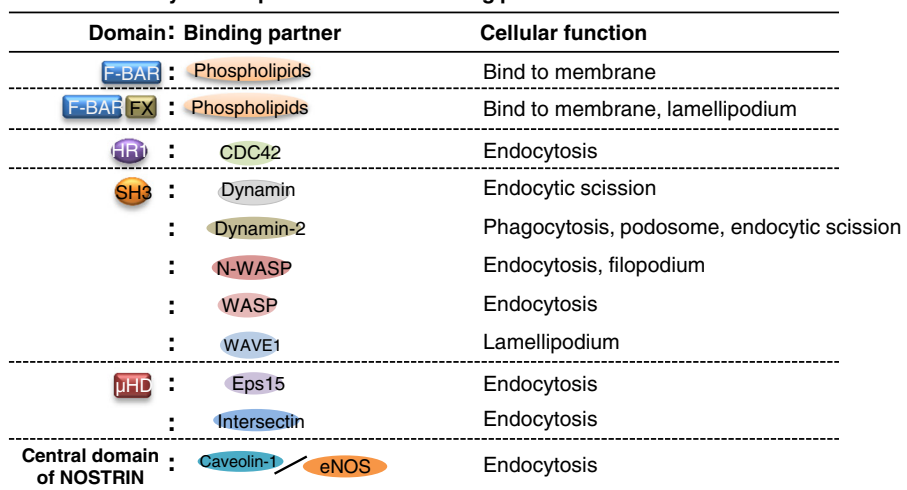

Figure 3 F-BAR protein domain interaction with specific partners and biological functions. Different domains of F-BAR proteins interact with specific binding partners (A) to perform various biological functions (B), including binding to membrane, endocytosis, endocytic scission, lamellipodium, phagocytosis, filopodium, lamellipodium, and podosome. Abbreviations: eNOS, endothelial nitric oxide synthase; WAVE, WASP family-Verproline homologous protein. For other abbreviations, refer to Figures 1 and 2.

caused microspike membrane changes in HeLa cells [25]. PACSIN2 is considered to facilitate the process of both endocytosis and filopodium-like formation.

\section{PSTPIP subfamily}

PSTPIP subfamily consists of two members, PSTPIP1 and PSTPIP2. PSTPIP1 has an N-terminal F-BAR domain, PEST motifs (peptide sequence rich in proline, glutamic acid, serine, and threonine), and a C-terminal SH3 domain, whereas PSTPIP2 lacks the PEST motifs and SH3 domain. PSTPIP1 was initially cloned as CD2binding protein 1 [26]. Similar to many other F-BAR proteins, PSTPIP1 binds to N-WASP and dynamin-2 to regulate endocytosis [27]. PSTPIP1 may have roles in
CD2-induced T-cell adhesion and receptor-mediated signaling [28] and lamellipodium and cytokinesis regulation in COS cells [29]. PSTPIP2 is mostly expressed in macrophages and may regulate filopodium formation and motility in macrophages [30]. Knockdown of PSTPIP2 in macrophages promoted the assembly of FBP17 and subsequent formation of podosome, suggesting an antagonism between FBP17 and PSTPIP2 to regulate actin polymerization during podosome formation [31].

\section{FCHSD subfamily}

FCHSD subfamily has two members, FCHSD1 and FCHSD2, each containing an F-BAR domain and two SH3 domains. FCHSD1 and FCHSD2 are mammalian orthologs 


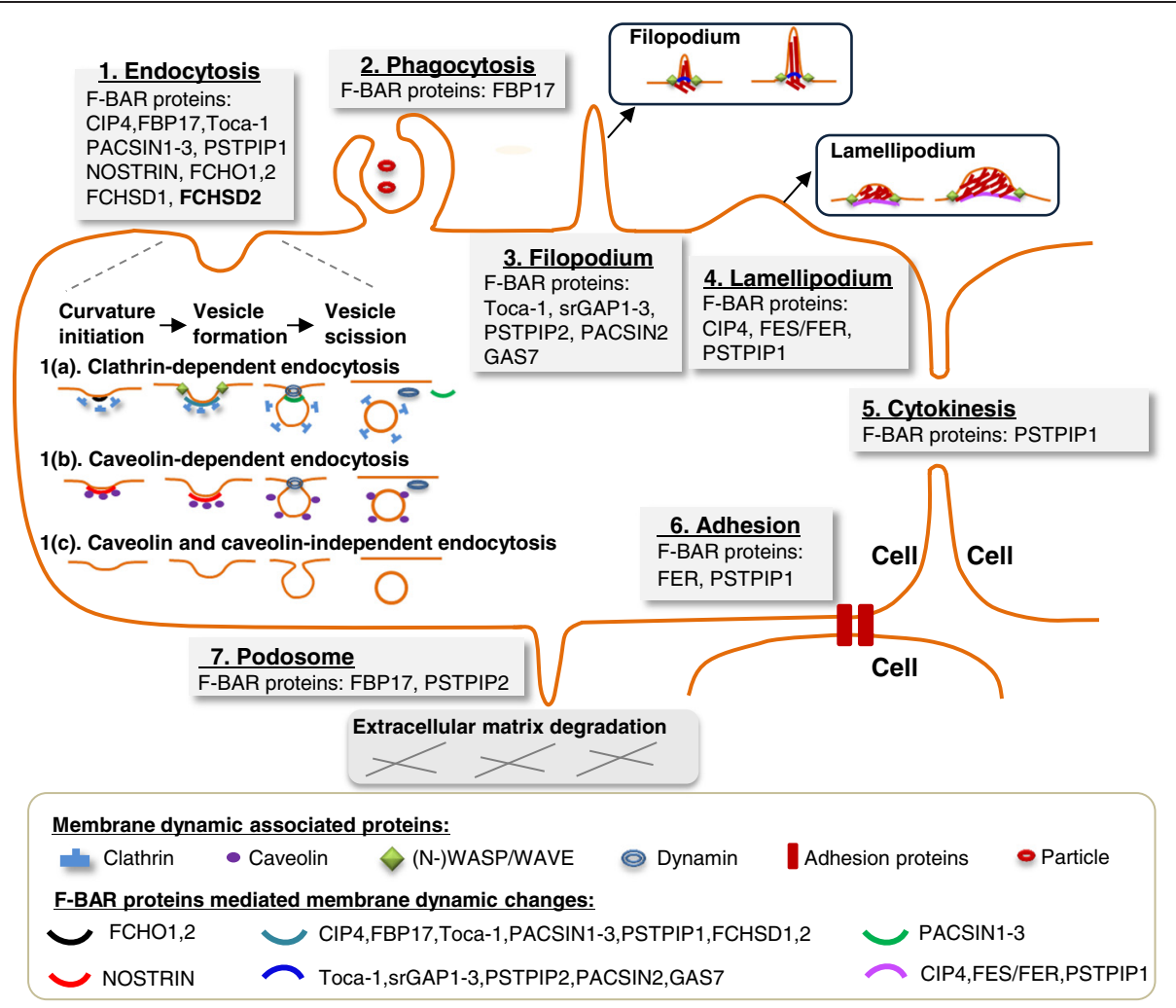

Figure 4 F-BAR protein-mediated membrane dynamic changes lead to seven major cellular functions. F-BAR proteins bind to cell membrane resulting in membrane curvature changes leading to seven major cellular functions. 1. Endocytosis consists of 1(a) clathrin-dependent endocytosis, 1(b) caveolin-dependent endocytosis, and 1(c) caveolin and caveolin-independent endocytosis. F-BAR proteins are found to be involved in clathrin or caveolin-dependent endocytosis. In clathrin-dependent endocytosis, FCHO1 and FCHO2 bind to cell membrane associated with clathrin to initiate curvature, while CIP4, FBP17, Toca-1, PACSIN1-3, PSTPIP1, and FCHSD1 and FCHSD2 mediate the formation of vesicle which involve other associated proteins including (N-)WASP or WAVE. PACSIN1-3 along with GTPase dynamin can bind to membrane and cause vesicle constriction, scission, and release. In caveolin-dependent endocytosis, NOSTRIN lead to the initiation and formation of caveolin-dependent endocytic vesicle. 2. Phagocytosis: FBP17 binds to the membrane to mediate the formation of phagocytosis in macrophage. 3. Filopodium: Toca-1, srGAP1-3, PSTPIP2, PACSIN2, and GAS7 can cause the formation of filopodium, which is a finger-like protrusion extended by the mobile edge of the cell. 4. Lamellipodium: CIP4, FES/FER, and PSTPIP1 lead to the formation of lamellipodium, which is a sheet-like protrusion on the mobile edge of the cell. 5. Cytokinesis: PSTPIP1 can migrate to the cleavage furrow to mediate cytokinesis, which is fundamental for the growth and development of all eukaryotic organisms. 6. Adhesion: FER and PSTPIP1 are involved in cell adhesion, which can mediate the process of immune response and the attachment of circulating inflammation cell to the blood vessel wall. 7. Podosome: FBP17 and PSTPIP2 mediate the formation of podosome, which regulates the extracellular matrix degradation. Symbols listed in the framed box indicate representative F-BAR proteins.

of drosophila nervous wreck (Nwk)2 and Nwk1, which interact with WASP via its first SH3 and cooperate with CDC42 to regulate endocytic actin assembly at drosophila larval neuromuscular junction [32]. Nwk1 and Nwk2 present with similar activity of I-BAR proteins, generating protrusion of cellular membrane [33]. The F-BAR domains of FCHSD1 and FCHSD2 were found abundantly in the area of protrusion structures of human HEK293T cells, supporting their roles in facilitating membrane protrusion.

FCHSD2 gene encodes a protein termed as Carom. Carom binds to membrane-associated guanylate kinase inverted 1 (MAGI-1) or calcium/calmodulin-dependent serine protein kinase (CASK), in a competitive manner, via its distinct sequences of the C-terminal region [34].
CASK is reported to inhibit cell cycle progress, while MAGI-1 is indicated to inhibit the migration of cancer cell and is required for junctional cell adhesion [35,36]. It is possible that Carom may regulate cell growth, migration, and adhesion via complex formation with CASK or MAGI.

\section{FES/FER subfamily}

The FES/FER subfamily includes two members, FES and FER, containing an N-terminal F-BAR domain, a central $\mathrm{SH} 2$ domain, and a $\mathrm{C}$-terminal tyrosine kinase domain. The region adjacent to the F-BAR domain also binds to phospholipids, thus named the F-BAR extension (FX) domain.

The F-BAR and FX domains of FES/FER function as a membrane-binding module to bind to phospholipids and 
induce the membrane curvature for lamellipodium formation and cell motility [37]. FER also regulates the phosphorylation of F-actin-binding protein cortactin, leading to the efficient fibroblast migration and integrinmediated cell adhesion [38].

\section{NOSTRIN}

NOSTRIN contains an N-terminal F-BAR domain and a C-terminal SH3 domain. NOSTRIN binds to N-WASP through its C-terminal SH3 domain to facilitate the endocytosis and recruit dynamin-2 for vesicle scission [39].

NOSTRIN is highly expressed in endothelial cells and highly vascularized organs, binding to the oxygenase domain of endothelial nitric oxide synthase (eNOS) [40]. NOSTRIN could directly interact with caveolin-1 and eNOS to form a ternary complex in Chinese hamster ovary cells stably expressing eNOS [41]. NOSTRIN overexpression triggers the caveolin-dependent endocytosis to translocate eNOS away from the membrane and decrease eNOS activity.

\section{GAS7}

GAS7 possesses an SH3 domain and a WW domain in the N-terminal, with its F-BAR domain positioned in the center region. Human GAS7 binds to N-WASP via SH3 domain to induce cell filopodium and regulate neurite outgrowth in differentiated brain cells [42]. Mouse GAS7 possesses a domain structure similar to human GAS7, but lacks the SH3 domain. Its WW domain can structurally resemble the human SH3 domain. Via WW domain, mouse GAS7 could interact with N-WASP and regulate the neurite outgrowth in hippocampal neurons [43].

\section{F-BAR protein-related functions in physiological and pathophysiological conditions}

As discussed above, F-BAR proteins may modulate seven cellular functions: endocytosis, phagocytosis, filopodium, lamellipodium, cytokinesis, adhesion, and podosome formation (Figure 4 and Table 1). These seven cellular functions are critical cellular processes regulated in physiological and pathophysiological conditions.

Endocytosis is the most common cellular function mediated by F-BAR proteins and their binding partners. In general, F-BAR protein binds to the membrane phospholipids via its F-BAR domain and recruits WASP/ $\mathrm{N}$-WASP and dynamin via SH3 domain to regulate the initiation and scission of endocytic vesicle (Figure 3) in clathrin or caveolin-dependent ways (Figure 4). Endocytosis could uptake and process extracellular materials, including proteins, DNAs, miRNA, apoptotic bodies, and microparticles $[44,45]$. Endocytic compartments can be released from cells to form exosomes, which can be uptaken by other cells and can transfer the above functional materials between cells [46]. In addition, endocytosis is also involved in the presentation of soluble antigens, soluble major histocompatibility complex-II (MHC-II)-restricted antigens, and MHC-I antigen cross presentation [47] (Figure 5). Furthermore, endocytosis promoted membrane trafficking and neuronal membrane protein turnover [48].

Phagocytosis is an action of macrophages (Figures 4 and 5). Opsonization is a special phagocytic process by which the solid particle is coated with opsonins to facilitate the attachment and internalization of the particle, like clearance of apoptotic bodies by a professional phagocytic cell [49]. Phagocytosis of lipase-aggregated low density lipoprotein could promote the formation of lipid-laden macrophages, known as foam cells [50]. Similar to macrophages, there are many other macrophage-like cells involved in phagocytosis of antigens, including Langham cell, microglial cell, Kupffer cell, dendritic cell, leukocyte, and granulocyte [51,52].

Filopodium is a finger-like protrusion and is necessary for neurite formation [16] (Figure 4). Whereas, lamellipodium is characterized by a dense network of short and branched actin bundles and may inhibit neurite formation [15]. Filopodium and lamellipodium are considered as the major controllers of migration of normal cells and as the mediator of metastatic cancer cell invasion [53] (Figure 5). Filopodium- and lamellipodium-mediated migrations promote inflammatory and immune-cell infiltration and homing [54], and is the first step in stem/progenitor cell repairing, bone marrow cell mobilization, and neointima formation [55-57]. During angiogenisis, filopodium and lamellipodium drive endothelial tip cell to form different membrane structures for sprouting angiogenisis [58]. Furthermore, filopodium and lamellipodium are capable of probing the environment to sense the presence of attractive guidance cues and lead the way to vasculogenesis and even genesis of tissues and organs [59].

Podosomes primarily regulate extracellular matrix (ECM) degradation and is associated with tumor metastasis. Tumor metastasis requires tumor cells to break through the basement membrane and invade through dense networks of interstitial ECM proteins. Filopodium and lamellipodium may also regulate ECM degradation as they connect the cytoskeleton to ECM via focal contact points [60]. It is reported that PSTPIP1 mutation caused the transition from podosome to filopodium and increased filopodium-mediated ECM degradation in macrophages [61].

Cytokinesis is a key process during cell proliferation which is a crucial process of development, tissue repair, and oncogenesis. In homeostasis status, normal cells accomplish a constant balance between cell growth and death to maintain proper tissue and organ size and patterning [62]. During oncogenesis, the progression of cellular changes ultimately led to the uncontrolled proliferation of tumor [63]. Thus, cytokinesis could drive cell proliferation in 
Table 1 Biological functions of F-BAR subfamilies

\begin{tabular}{|c|c|c|c|c|c|c|c|}
\hline \multirow[t]{2}{*}{ Proteins } & \multicolumn{7}{|c|}{ Cellular functions } \\
\hline & Endocytosis & Phagocytosis & Filopodium & Lamellipodium & Cytokinesis & Adhesion & Podosome \\
\hline \multicolumn{8}{|l|}{ 1. CIP4 subfamily } \\
\hline CIP4 & $\sqrt{ }$ & N/A & N/A & $\sqrt{ }$ & N/A & N/A & N/A \\
\hline FBP17 & $\sqrt{ }$ & $\sqrt{ }$ & N/A & N/A & N/A & N/A & $\sqrt{ }$ \\
\hline Toca-1 & $\sqrt{ }$ & N/A & $\sqrt{ }$ & N/A & N/A & N/A & N/A \\
\hline \multicolumn{8}{|l|}{ 2. FCHOs subfamily } \\
\hline $\mathrm{FCHO} 1$ & $\sqrt{ }$ & N/A & $\mathrm{N} / \mathrm{A}$ & $\mathrm{N} / \mathrm{A}$ & $\mathrm{N} / \mathrm{A}$ & $\mathrm{N} / \mathrm{A}$ & $\mathrm{N} / \mathrm{A}$ \\
\hline $\mathrm{FCHO} 2$ & $\sqrt{ }$ & N/A & N/A & N/A & $\mathrm{N} / \mathrm{A}$ & $\mathrm{N} / \mathrm{A}$ & N/A \\
\hline \multicolumn{8}{|l|}{ 3. srGAPs subfamily } \\
\hline srGAP1 & N/A & N/A & $\sqrt{ }$ & N/A & N/A & N/A & N/A \\
\hline srGAP2 & N/A & N/A & $\sqrt{ }$ & N/A & $\mathrm{N} / \mathrm{A}$ & N/A & N/A \\
\hline srGAP3 & N/A & N/A & $\sqrt{ }$ & N/A & N/A & N/A & N/A \\
\hline \multicolumn{8}{|l|}{ 4. PACSINs subfamily } \\
\hline PACSIN1 & $\sqrt{ }$ & N/A & N/A & N/A & $\mathrm{N} / \mathrm{A}$ & N/A & N/A \\
\hline PACSIN2 & $\sqrt{ }$ & $\mathrm{N} / \mathrm{A}$ & $\sqrt{ }$ & N/A & N/A & N/A & N/A \\
\hline PACSIN3 & $\sqrt{ }$ & N/A & N/A & N/A & N/A & N/A & $\mathrm{N} / \mathrm{A}$ \\
\hline \multicolumn{8}{|l|}{ 5. PSTPIPs subfamily } \\
\hline PSTPIP1 & $\sqrt{ }$ & N/A & N/A & $\sqrt{ }$ & $\sqrt{ }$ & $\sqrt{ }$ & N/A \\
\hline PSTPIP2 & N/A & N/A & $\sqrt{ }$ & N/A & N/A & N/A & $\sqrt{ }$ \\
\hline \multicolumn{8}{|l|}{ 6. FCHSDs subfamily } \\
\hline FCHSD1 & $\sqrt{ }$ & N/A & N/A & N/A & $\mathrm{N} / \mathrm{A}$ & $\mathrm{N} / \mathrm{A}$ & N/A \\
\hline FCHSD2 & $\sqrt{ }$ & N/A & $\mathrm{N} / \mathrm{A}$ & $\mathrm{N} / \mathrm{A}$ & N/A & $\mathrm{N} / \mathrm{A}$ & $\mathrm{N} / \mathrm{A}$ \\
\hline \multicolumn{8}{|l|}{ 7. FES/FER subfamily } \\
\hline FES & N/A & N/A & $\mathrm{N} / \mathrm{A}$ & $\sqrt{ }$ & $\mathrm{N} / \mathrm{A}$ & N/A & N/A \\
\hline FER & N/A & N/A & N/A & $\sqrt{ }$ & N/A & $\sqrt{ }$ & N/A \\
\hline 8. NOSTRIN subfamily & $\sqrt{ }$ & N/A & N/A & N/A & N/A & N/A & N/A \\
\hline 9. GAS7 subfamily & N/A & N/A & $\sqrt{ }$ & $\mathrm{N} / \mathrm{A}$ & $\mathrm{N} / \mathrm{A}$ & N/A & $\mathrm{N} / \mathrm{A}$ \\
\hline
\end{tabular}

F-BAR proteins are implicated in various biological functions via interaction with specific binding partners. For F-BAR protein abbreviations, refer to Figure 1.

different status to maintain normal cell homeostasis and tumor cell oncogenesis.

Cell adhesion is the binding of a cell to a surface or substrate, such as blood vessel wall or ECM, which can mediate immune response in different tissues. It is reported that endothelial cell adhesion molecules mediate the attachment of circulating inflammation cells to the blood vessel wall and subsequently their extravasation into perivascular tissues [64].

In summary, F-BAR proteins are involved in controlling endocytosis, phagocytosis, filopodium, lamellipodium, cytokinesis, adhesion, and podosome formation, and are suggested to be relevant to various diseases and disorder conditions (Figure 5). Based on the above functional analysis, we suspect that F-BAR proteins might also be involved in ischemic vascular diseases, autoimmune diseases, graft-versus-host disease, and lipid metabolism, which needs to be explored in the future.

\section{Roles of F-BAR proteins in diseases and developmental disorders}

As indicated in Table 2, F-BAR expression change and gene mutation is associated with seven kinds of disease and disorder conditions, including developmental disorders, neurological diseases, autoinflammatory diseases, cancer invasion, cardiac hypertrophy, glucose uptake, and renal dysfunction.

\section{Developmental and vascular disorders Developmental disorders}

CIP4, PACSIN3, and FCHO1 are associated with developmental disorders. CIP4 is reported to inhibit actin nucleation of embryonic morphogenesis in drosophila embryogenesis [65]. Overexpression of CIP4 antagonized actin nucleation associated with Diaphanous (Dia), which is an actin nucleator responsible for F-actin formation in drosophila membrane compartmentalization. 


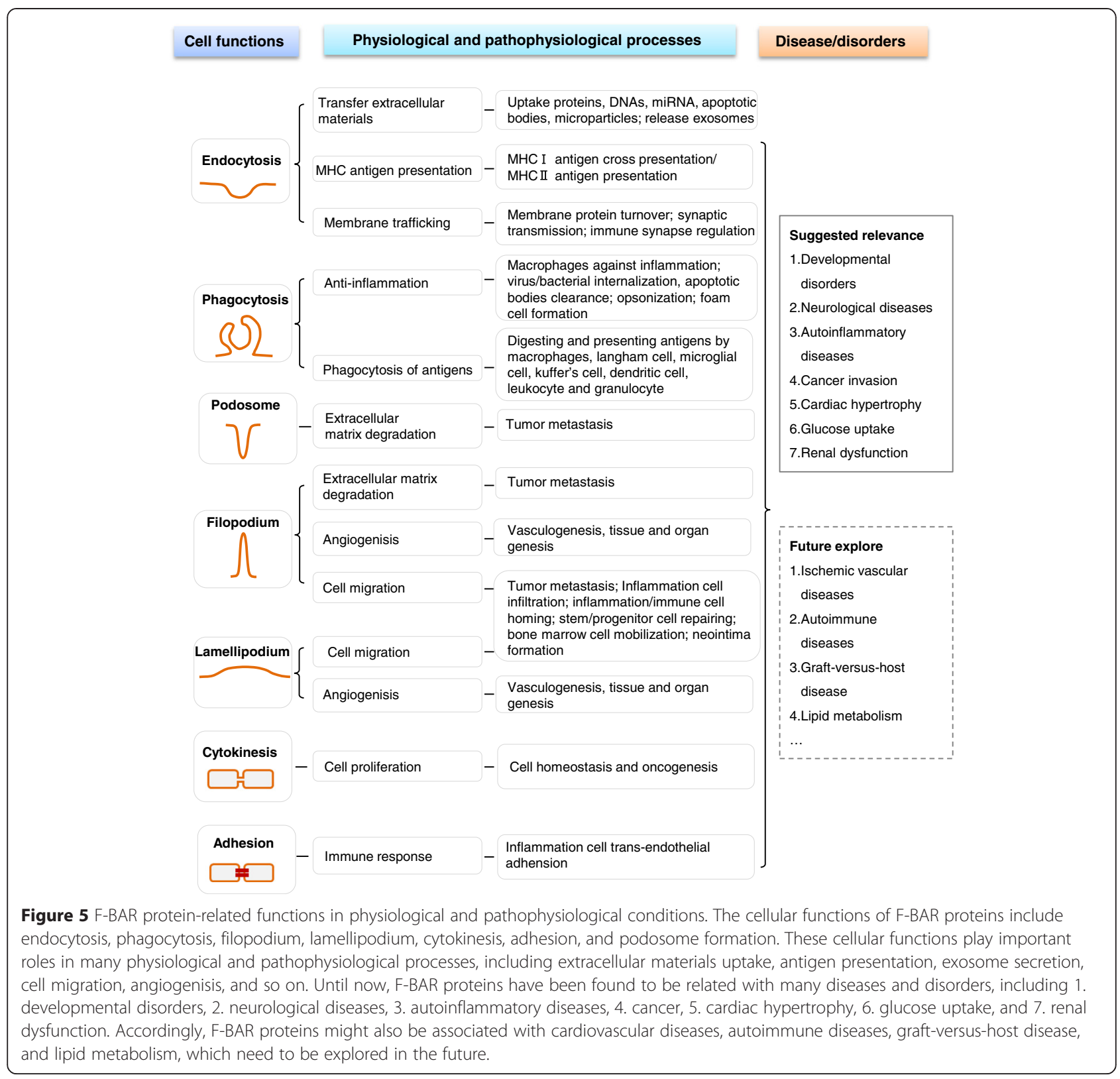

PACSIN3 may be related with early notochord formation during embryonic development in zebrafish, as axial mesodermal cell failed to migrate and the midline convergence of notochord precursors was defective in PACSIN3deleted embryos [66]. FCHO1 was found interacting with $\mathrm{Bmp}$ receptor Alk8 and positively regulating $\mathrm{Bmp}$ signal transmission in dorsoventral patterning of zebrafish embryos [67].

\section{Vascular disorders}

Interestingly, NOSTRIN is reported to be necessary for proper vascular development in zebrafish and postnatal retinal angiogenesis in mice [68]. Knockdown of NOSTRIN in zebrafish embryos caused reduction of filopodium number and length and altered tip cell morphology, leading to abnormal intersegmental vessel trajectory. In NOSTRIN knockout mice, postnatal retinal angiogenesis was impaired due to the impairment of NOSTRIN-mediated fibroblast growth factor 2 signal transduction in endothelial cells, resulting in the suppression of endothelial tip cell migration.

\section{Neurological disorders}

\section{Neurodevelopmental disorders}

Altered expression and mutation of F-BAR family was associated with neurological disorders in human and 
Table 2 Altered expression/mutation of F-BAR proteins in diseases and developmental disorders

\begin{tabular}{|c|c|c|c|}
\hline Diseases and disorders & Species & F-BAR protein changes & PMID ID\# \\
\hline \multicolumn{4}{|l|}{ Developmental and vascular disorders } \\
\hline Embryonic defects & Drosophila, zebrafish & CIP4个, PACSIN3 $\downarrow$ & 23424199, 19997509 \\
\hline Dorsoventral defects & Zebrafish & FCHO1 $\downarrow$ & 22484487 \\
\hline Vascular defects & Zebrafish & NOSTRIN $\downarrow$ & 22751148 \\
\hline Postnatal retinal angiogenisis & Mice & NOSTRIN $\downarrow$ & 22751148 \\
\hline \multicolumn{4}{|l|}{ Neurological disorders } \\
\hline Neurodevelopmental disorders & Mice & $\operatorname{srGAP} 2 \downarrow, \operatorname{srGAP} 3 \downarrow$ & 23505444,22820399 \\
\hline $3 p$ syndrome & Human & srGAP3 deletion & 19760623 \\
\hline Huntington's disease & Human & CIP4个, PACSIN1 $\downarrow$ & 12604778,23852340 \\
\hline Epileptic seizures & Mice & PACSIN1 $\downarrow$ & 21926968 \\
\hline \multicolumn{4}{|l|}{ Autoinflammatory diseases } \\
\hline Wiskott-Aldrich syndrome & Human & FBP17 $\downarrow$ & 19155218 \\
\hline PAPA syndrome & Human & PSTPIP1 mutation & 21532836 \\
\hline Chronic multifocal osteomyelitis & Mice & PSTPIP2 mutation & 16122996 \\
\hline \multicolumn{4}{|l|}{ Cancers } \\
\hline Bladder tumor & Human & FBP17个 & 21421245 \\
\hline Breast tumor & Human & CIP4 $\downarrow$ & 21525036 \\
\hline Leukemia & Human & 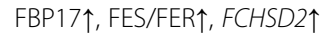 & $11438682,22201778,22902056$ \\
\hline Cardiac hypertrophy & Rat & $\mathrm{CIP} 4 \uparrow$ & 23915320 \\
\hline Glucose uptake elevation & Rat, mice & 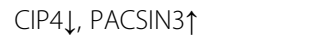 & 19509061,17320047 \\
\hline Renal dysfunction & Human & $\mathrm{CIP} 4 \uparrow$ & 22745576 \\
\hline
\end{tabular}

F-BAR protein expression and mutations are observed in various disease and developmental disorders in human, mice, rat, zebrafish, and drosophila in publications cited by PMID\#. FCHSD2 was found differentially expressed in a cardiovascular disease system in our recent study. Abbreviations: $3 p$ syndrome, 3p25-p26 deletion syndrome; PAPA syndrome, Pyogenic arthritis, pyoderma gangrenosum, and acne syndrome.

mice. The expression of srGAP3 was found to be reduced in childhood-onset schizophrenia proband [69]. srGAP3 knockout mice showed various behavioral phenotypes and complex neuroanatomical changes, including impaired spontaneous alternation and social behavior, enlarged lateral ventricles and spines, and increased basal activity of GTPase Rac1 [70]. It is reported that srGAP2 could act through srGAP3-Rac1 signaling to attenuate neuronal differentiation and neurite outgrowth in mouse neuroblastoma cells [22]. Overexpression of srGAP2C, srGAP2 with a truncated F-BAR domain, could impaire its function, leading to the neoteny of dendritic spine maturation in mouse neurons [71].

\section{$3 p$ syndrome}

Distal 3p25-p26 chromosome deletion syndrome (3p syndrome) is a rare contiguous gene disorder characterized by low birth weight, mental retardation, telecanthus, ptosis, and micrognathia. srGAP3 was disrupted and functionally inactivated by a translocation breakpoint in a patient with 3p syndrome [72]. Microarray analysis of 14 patients with $3 p$ syndrome revealed that srGAP3 was the major determinant of mental retardation [73].

\section{Huntington's disease}

Huntington's disease (HD) is caused by expansion of a polyglutamine repeat within the $\mathrm{N}$-terminal region of huntingtin and present with severe neurodegenerative disorders. CIP4 interacted with huntingtin via SH3 domain, and overexpression of CIP4 induced the death of striatal neurons during HD pathogenesis [74]. PACSIN1 could also interact with huntingtin to interfere PACSIN1 mediated-endocytic removal of glutamate NMDA receptor subunit 3A (GluN3A), leading to age inappropriate synapse destabilization during HD pathogenesis [75].

\section{Epileptic seizures}

PACSIN1 complex with dynamin-1 may act as pivotal membrane anchoring factor for dynamin-1 during regeneration of synaptic vesicles. Gene deficiency of PACSIN1 or dynamin-1 in mice led to the development of epileptic seizures correlating with excessive hippocampal network activity [76].

\section{Autoinflammatory diseases \\ Wiskott-Aldrich syndrome (WAS)}

WAS is an X chromosome-linked immunodeficiency disorder, characterized by eczema, thrombocytopenia, immune 
deficiency, and bloody diarrhea. WAS patients lack expression of WASP which binds to F-BAR protein FBP17 and regulates membrane dynamic changes (Figure 3 ). WAS patients presented with defects in forming WASPFBP17-dynamin complex and podosomes/phagocytic cups in macrophages [17]. In addition, CIP4 may be related to WAS as CIP4-null mice developed thrombocytopenia, characterized by fewer proplatelet-like extensions and more rigid membrane, a phenotype observed in WAS patients [77].

\section{PAPA syndrome}

PAPA syndrome (pyogenic arthritis, pyoderma gangrenosum, and acne) is an autosomal dominant arising from PSTPIP1 gene mutation in the SH3 domain of
PSTPIP1 [78]. It impaired PSTPIP1-WASP binding and induced the transition from podosome to filopodium formation. Increased filopodium formation leads to ECM degradation and enhanced invasive properties in PAPA syndrome.

\section{Chronic multifocal osteomyelitis}

Chronic recurrent multifocal osteomyelitis (CRMO) is a human autoinflammatory disorder that primarily affects bone, skin, or gastrointestinal tract. A missense mutation (L98P) of PSTPIP2 in mice led to pathophysiological changes similar to CRMO, called chronic multifocal osteomyelitis in mice [79] with increased IL-1 $\beta$ secretion in neutrophils and the inflammasome-independent IL$1 \beta$-mediated autoinflammatory reactions [80].

Table 3 F-BAR proteins changes and potential mechanisms in diseases and pathophysiological conditions

\begin{tabular}{|c|c|c|c|c|c|}
\hline Proteins & Changes & Disease/condition & Species & Mechanisms & PMID ID\# \\
\hline \multicolumn{6}{|c|}{ 1. CIP4 subfamily } \\
\hline \multirow[t]{5}{*}{ CIP4 } & $\uparrow$ & Embryogenesis & Drosophila & Inhibits actin nucleation associated with Diaphanous & 23424199 \\
\hline & $\uparrow$ & Huntington's disease & Human & Induces striatal neuron death & 12604778 \\
\hline & $\downarrow$ & Breast tumor & Human & Suppresses Src-induced tumor cell invasion & 21525036 \\
\hline & $\downarrow$ & Cardiac hypertrophy & Rat & Inhibits myocyte hypertrophy & 23915320 \\
\hline & $\downarrow$ & Glucose uptake & Rat & Induces glucose uptake via GLUT4 endocytosis & 19509061 \\
\hline \multirow[t]{3}{*}{ FBP17 } & $\uparrow$ & Leukemia & Human & A fusion partner of mixed lineage leukemia & 11438682 \\
\hline & $\downarrow$ & Bladder tumor & Human & Inhibits bladder tumor cell invasion & 21421245 \\
\hline & $\downarrow$ & Wiskott-Aldrich syndrome & Human & Suppresses podosomes/phagocytic cup formation & 19155218 \\
\hline \multicolumn{6}{|c|}{ 2. FCHO subfamily } \\
\hline $\mathrm{FCHO} 1$ & $\downarrow$ & Dorsoventral defects & Zebrafish & Suppresses Bmp signal transmission & 22484487 \\
\hline \multicolumn{6}{|c|}{ 3.srGAP subfamily } \\
\hline srGAP2 & $\downarrow$ & Neuronal development & Mice & Suppresses neuronal development through srGAP3 & 23505444 \\
\hline \multirow[t]{2}{*}{ srGAP3 } & $\downarrow$ & Neuronal development & Mice & Induces basal activity of Rac1 & 22820399 \\
\hline & Deletion & $3 p$ syndrome & Human & Gene is deleted, mechanism not analyzed & 19760623 \\
\hline \multicolumn{6}{|c|}{ 4. PACSIN subfamily } \\
\hline \multirow[t]{2}{*}{ PACSIN1 } & $\downarrow$ & Epileptic seizures & Mice & Induces hippocampal network activity & 21926968 \\
\hline & $\downarrow$ & Huntington's disease & Human & Induces age inappropriate synapse destablization & 23852340 \\
\hline \multirow[t]{2}{*}{ PACSIN3 } & $\downarrow$ & Embryonic defects & Zebrafish & Suppresses early formation of notochord & 19997509 \\
\hline & $\uparrow$ & Glucose uptake & Mice & Induces glucose uptake via GLUT1 trafficking & 17320047 \\
\hline \multicolumn{6}{|c|}{ 5. PSTPIP subfamily } \\
\hline PSTPIP1 & Mutation & PAPA syndrome & Human & Gene mutation alters WASP activity & 21532836 \\
\hline PSTPIP2 & Mutation & Chronic multifocal osteomyelitis & Mice & Gene mutation and IL-1 $\beta$ induces inflammation & 16122996 \\
\hline \multicolumn{6}{|c|}{ 6. FCHSD subfamily } \\
\hline FCHSD2 & $\uparrow$ & Leukemia & Human & Increases leukemia chemoresistance & 22902056 \\
\hline \multicolumn{6}{|c|}{ 7. FES/FER subfamily } \\
\hline FES/FER & $\uparrow$ & Leukemia & Human & Induces growth and survival signaling in leukemia & 22201778 \\
\hline \multicolumn{6}{|c|}{ 8. NOSTRIN subfamily } \\
\hline NOSTRIN & $\downarrow$ & Postnatal retinal angiogenisis & Mice & Suppresses endothelial tip cell migration & 22751148 \\
\hline
\end{tabular}

F-BAR protein expression is observed in various disease and pathophysiological conditions via suggested mechanisms in human, mice, rat, zebrafish, and drosophila. Relevant publications are cited by PMID\#. For other abbreviations, refer to Table 2. 


\section{Cancers}

\section{Bladder tumor}

FBP17 was found expressed in three bladder tumor cell lines and primary bladder tumor cells from patients [81]. FBP17 knockdown significantly decreased the podosome formation and inhibited the invasive capacity in tumor cells [81].

\section{Breast tumor}

CIP4 suppressed Src-induced invasion in MDA-MB-231 breast tumor cells [82]. CIP4 knockdown cells inhibited endocytosis of type I matrix metalloprotease, leading to increased ECM degradation and breast tumor cell invasion.

\section{Leukemia}

Rearrangement of the mixed lineage leukemia (MLL) gene at chromosome $11 \mathrm{q} 23$ is commonly detected in leukemia. FBP17 is a fusion partner of the MLL gene at 11q23 and may be related to MLL [83]. FES/FER also implicated oncogenic KIT/FLT3 growth and survival signaling in leukemia [84]. Activated alleles of FES are potent inducers of myeloid differentiation. Knockdown of FCHSD2 enhanced chemosensitivity, whereas its overexpression increased cellular chemoresistance in U937 cells [85]. FCHSD2 levels are recognized as a clinical predictor for chemotherapy response in leukemia patients.

\section{Cardiac hypertrophy}

It is suggested that CIP4 regulated intracellular hypertrophic signal transduction to control the growth of myocytes in heart disease. Knockdown of CIP4 inhibited myocyte hypertrophy and the inhibition could be rescued by expression of a recombinant CIP4 [86].

\section{Glucose uptake}

CIP4 co-localized with glucose transporter (GLUT) 4 in L6 GLUT4 myc-expressing myoblasts [87]. Knockdown of CIP4 increased glucose uptake by elevating cell surface GLUT4. Overexpression of PACSIN3 in adipocytes caused an inhibition of GLUT1 endocytosis and induced GLUT1 membrane localization, leading to the elevation of glucose uptake [88].

\section{Renal dysfunction}

CIP4 is highly expressed in tubular epithelia of 5/6nephrectomized rat models and TGF- $\beta 1$ treated human kidney (HK)-2 cells [89]. Overexpression of CIP4 promoted renal epithelial-mesenchymal transition (EMT) and induced ECM deposition in TGF- $\beta 1$-treated HK-2 cells.

Finally, we summarize the F-BAR protein expression changes and potential mechanisms in disease and pathophysiological conditions in Table 3. F-BAR protein expression change and mutations are associated with developmental disorders, neurological and autoinflammatory diseases, cancer invasion, cardiac hypertrophy, glucose uptake, and renal dysfunction. We suspect that F-BAR proteins contribute to pathophysiological conditions via cell membrane dynamic modulation and subsequent cell function changes as described in Figure 5. F-BAR family proteins may provide novel potential therapeutic targets for neurological and autoinflammatory diseases, cardiovascular disorder, cancer, and metabolic disorders.

\section{Future perspective}

F-BAR proteins can recruit different binding partners to regulate membrane dynamics and cellular functions. Considering the structure features and functional implications of F-BAR proteins described above, we anticipate that F-BAR proteins modulate physiological and pathophysiological processes via transferring extracellular materials, regulating cell trafficking and mobility, presenting antigens, mediating ECM degradation, and transmitting signaling for cell proliferation. The continued efforts to explore fundamental details of F-BAR family structure, partner, signaling, and regulation would provide important insights to our understanding and to the identification of their therapeutic potential.

\section{Abbreviations}

Arp2/3: Actin-related protein 2/3; BAR: Bin/Amphiphysin/Rvs; CIP4: CDC42-interacting protein 4; CRIB: CDC42-Rac interactive binding; ECM: Extracellular matrix; F-actin: Filamentous actin; F-BAR: Fes/CIP4 homology-Bin/Amphiphysin/Rvs; FCHO: FCH only; FCHSD: FCH and double SH3 domain proteins; FER: FES related; FX: F-BAR extension; GAS7: Growth arrest-specific 7; HR1: Protein kinase C-related kinase homology region 1; I-BAR: Inverse BAR; N-BAR: $\mathrm{N}$-terminal amphipathic helix BAR; NOSTRIN: Nitric oxide synthase traffic inducer; N-WASP: Neural Wiskott-Aldrich syndrome protein; PACSIN: Protein kinase $C$ and casein kinase 2 substrates in neurons; RhoGAP: Rho GTPase-activating protein; SH2: Src homology-2; SH3: Src homology-3; srGAP: Slit-Robo GTPase-activating protein; $\mu \mathrm{HD}$ : $\mu$-homology domain; VCA: Verprolin, cofilin, acidic; WASP: Wiskott-Aldrich syndrome protein; WAVE: WASP family verproline-homologous protein.

\section{Competing interests}

The authors declare that they have no competing interests.

\section{Authors' contributions}

HW is in charge of the study and involved in the study design, manuscript writing, and finalizing. $X Y$ and $X Z$ participated in the study design and manuscript drafting. SL and XX carried out the molecular studies and manuscript drafting. All authors read and approved the final manuscript.

\section{Acknowledgements}

The authors acknowledge the contributions of Merlin Abner Paz, Temple University for the English language editing.

\section{Sources of funding}

This work was supported in part by the National Institutes of Health (NIH) grant numbers: HL67033, HL77288, HL82774, HL110764, and HL117654 (HW); HL9445, HL108910, and HL116917 (XFY); the Shanghai Sailing Program of China 14YF1405700; and the National Natural Science Foundation of China 81400228 (SXL).

\section{Author details}

${ }^{1}$ Department of Cardiology, Changhai Hospital, Second Military Medical University, Shanghai 200433, China. ${ }^{2}$ Center for Metabolic Disease Research, Department of Pharmacology, Temple University School of Medicine, Philadelphia, PA 19140, USA. ${ }^{3}$ Center for Cardiovascular Research, Department of Pharmacology, Temple University School of Medicine, 
Philadelphia, PA 19140, USA. ${ }^{4}$ Center for Thrombosis Research, Department of Pharmacology, Temple University School of Medicine, Philadelphia, PA 19140, USA.

\section{Received: 16 February 2015 Accepted: 27 April 2015} Published online: 09 May 2015

\section{References}

1. Frost A, Unger VM, De Camilli P. The BAR domain superfamily: membranemolding macromolecules. Cell. 2009;137:191-6.

2. Aspenstrom P. A Cdc42 target protein with homology to the non-kinase domain of FER has a potential role in regulating the actin cytoskeleton. Curr Biol. 1997;7:479-87.

3. Aspenstrom P. Roles of F-BAR/PCH proteins in the regulation of membrane dynamics and actin reorganization. Int Rev Cell Mol Biol. 2009;272:1-31.

4. Ahmed S, Bu W, Lee RT, Maurer-Stroh S, Goh WI. F-BAR domain proteins: families and function. Commun Integr Biol. 2010;3:116-21.

5. Takenawa T. Phosphoinositide-binding interface proteins involved in shaping cell membranes. Proc Jpn Acad Ser B Phys Biol Sci. 2010;86:509-23.

6. Suetsugu S, Toyooka K, Senju Y. Subcellular membrane curvature mediated by the BAR domain superfamily proteins. Semin Cell Dev Biol. 2010;21:340-9.

7. Roberts-Galbraith RH, Gould KL. Setting the F-BAR: functions and regulation of the F-BAR protein family. Cell Cycle. 2010;9:4091-7.

8. Shimada A, Niwa H, Tsujita K, Suetsugu S, Nitta K, Hanawa-Suetsugu K, et al. Curved EFC/F-BAR-domain dimers are joined end to end into a filament for membrane invagination in endocytosis. Cell. 2007;129:761-72.

9. Scita G, Confalonieri S, Lappalainen P, Suetsugu S. IRSp53: crossing the road of membrane and actin dynamics in the formation of membrane protrusions. Trends Cell Biol. 2008;18:52-60.

10. Takenawa T, Miki H. WASP and WAVE family proteins: key molecules for rapid rearrangement of cortical actin filaments and cell movement. J Cell Sci. 2001;114:1801-9.

11. Itoh T, Erdmann KS, Roux A, Habermann B, Werner H, De Camilli P. Dynamin and the actin cytoskeleton cooperatively regulate plasma membrane invagination by BAR and F-BAR proteins. Dev Cell. 2005;9:791-804.

12. Feng Y, Hartig SM, Bechill JE, Blanchard EG, Caudell E, Corey SJ. The Cdc42-interacting protein-4 (CIP4) gene knock-out mouse reveals delayed and decreased endocytosis. J Biol Chem. 2010;285:4348-54.

13. Hu J, Troglio F, Mukhopadhyay A, Everingham S, Kwok E, Scita G, et al. F-BAR-containing adaptor CIP4 localizes to early endosomes and regulates epidermal growth factor receptor trafficking and downregulation. Cell Signal. 2009:21:1686-97.

14. Saengsawang W, Mitok K, Viesselmann C, Pietila L, Lumbard DC, Corey SJ, et al. The F-BAR protein CIP4 inhibits neurite formation by producing lamellipodial protrusions. Curr Biol. 2012;22:494-501.

15. Tanaka E, Sabry J. Making the connection: cytoskeletal rearrangements during growth cone guidance. Cell. 1995;83:171-6.

16. Dent EW, Kwiatkowski AV, Mebane LM, Philippar U, Barzik M, Rubinson DA, et al. Filopodia are required for cortical neurite initiation. Nat Cell Biol. 2007:9:1347-59.

17. Tsuboi S, Takada H, Hara T, Mochizuki N, Funyu T, Saitoh H, et al. FBP17 mediates a common molecular step in the formation of podosomes and phagocytic cups in macrophages. J Biol Chem. 2009;284:8548-56.

18. Bu W, Chou AM, Lim KB, Sudhaharan T, Ahmed S. The Toca-1-N-WASP complex links filopodial formation to endocytosis. J Biol Chem. 2009;284:11622-36.

19. Henne WM, Boucrot E, Meinecke M, Evergren E, Vallis $Y$, Mittal $R$, et al. $\mathrm{FCHo}$ proteins are nucleators of clathrin-mediated endocytosis. Science. 2010;328:1281-4

20. Soderling SH, Binns KL, Wayman GA, Davee SM, Ong SH, Pawson T, et al The WRP component of the WAVE-1 complex attenuates Rac-mediated signalling. Nat Cell Biol. 2002:4:970-5.

21. Guerrier S, Coutinho-Budd J, Sassa T, Gresset A, Jordan NV, Chen K, et al. The F-BAR domain of srGAP2 induces membrane protrusions required for neuronal migration and morphogenesis. Cell. 2009;138:990-1004.

22. Ma Y, Mi YJ, Dai YK, Fu HL, Cui DX, Jin WL. The inverse F-BAR domain protein srGAP2 acts through srGAP3 to modulate neuronal differentiation and neurite outgrowth of mouse neuroblastoma cells. PLoS One. 2013:8:e57865.

23. Vogt DL, Gray CD, Young 3rd WS, Orellana SA, Malouf AT. ARHGAP4 is a novel RhoGAP that mediates inhibition of cell motility and axon outgrowth. Mol Cell Neurosci. 2007;36:332-42.
24. Qualmann B, Kelly RB. Syndapin isoforms participate in receptor-mediated endocytosis and actin organization. J Cell Biol. 2000;148:1047-62.

25. Shimada A, Takano K, Shirouzu M, Hanawa-Suetsugu K, Terada T, Toyooka K, et al. Mapping of the basic amino-acid residues responsible for tubulation and cellular protrusion by the EFC/F-BAR domain of pacsin2/Syndapin II. FEBS Lett. 2010;584:1111-8.

26. Li J, Nishizawa K, An W, Hussey RE, Lialios FE, Salgia R, et al. A cdc15-like adaptor protein (CD2BP1) interacts with the CD2 cytoplasmic domain and regulates CD2-triggered adhesion. EMBO J. 1998;17:7320-36.

27. Tsujita K, Suetsugu S, Sasaki N, Furutani M, Oikawa T, Takenawa T. Coordination between the actin cytoskeleton and membrane deformation by a novel membrane tubulation domain of $\mathrm{PCH}$ proteins is involved in endocytosis. J Cell Biol. 2006;172:269-79.

28. Badour K, Zhang J, Shi F, McGavin MK, Rampersad V, Hardy LA, et al. The Wiskott-Aldrich syndrome protein acts downstream of CD2 and the CD2AP and PSTPIP1 adaptors to promote formation of the immunological synapse. Immunity. 2003;18:141-54.

29. Spencer S, Dowbenko D, Cheng J, Li W, Brush J, Utzig S, et al. PSTPIP: a tyrosine phosphorylated cleavage furrow-associated protein that is a substrate for a PEST tyrosine phosphatase. J Cell Biol. 1997;138:845-60.

30. Chitu V, Pixley FJ, Macaluso F, Larson DR, Condeelis J, Yeung YG, et al. The PCH family member MAYP/PSTPIP2 directly regulates F-actin bundling and enhances filopodia formation and motility in macrophages. Mol Biol Cell. 2005;16:2947-59.

31. Tsujita K, Kondo A, Kurisu S, Hasegawa J, Itoh T, Takenawa T. Antagonistic regulation of F-BAR protein assemblies controls actin polymerization during podosome formation. J Cell Sci. 2013;126:2267-78.

32. Rodal AA, Motola-Barnes RN, Littleton JT. Nervous wreck and Cdc42 cooperate to regulate endocytic actin assembly during synaptic growth. J Neurosci. 2008;28:8316-25

33. Becalska AN, Kelley CF, Berciu C, Stanishneva-Konovalova TB, Fu X, Wang S, et al. Formation of membrane ridges and scallops by the F-BAR protein nervous wreck. Mol Biol Cell. 2013;24:2406-18.

34. Ohno H, Hirabayashi S, Kansaku A, Yao I, Tajima M, Nishimura W, et al. Carom: a novel membrane-associated guanylate kinase-interacting protein with two SH3 domains. Oncogene. 2003;22:8422-31.

35. Sun R, Su Y, Zhao X, Qi J, Luo X, Yang Z, et al. Human calcium/calmodulindependent serine protein kinase regulates the expression of $\mathrm{p} 21$ via the E2A transcription factor. Biochem J. 2009;419:457-66.

36. Sakurai A, Fukuhara S, Yamagishi A, Sako K, Kamioka Y, Masuda M, et al. MAGI-1 is required for Rap1 activation upon cell-cell contact and for enhancement of vascular endothelial cadherin-mediated cell adhesion. Mol Biol Cell. 2006;17:966-76

37. Itoh T, Hasegawa J, Tsujita K, Kanaho Y, Takenawa T. The tyrosine kinase Fer is a downstream target of the PLD-PA pathway that regulates cell migration. Sci Signal. 2009;2:ra52.

38. Sangrar W, Gao Y, Scott M, Truesdell P, Greer PA. Fer-mediated cortactin phosphorylation is associated with efficient fibroblast migration and is dependent on reactive oxygen species generation during integrin-mediated cell adhesion. Mol Cell Biol. 2007;27:6140-52.

39. Icking A, Matt S, Opitz N, Wiesenthal A, Muller-Esterl W, Schilling K. NOSTRIN functions as a homotrimeric adaptor protein facilitating internalization of eNOS. J Cell Sci. 2005;118:5059-69.

40. Zimmermann K, Opitz N, Dedio J, Renne C, Muller-Esterl W, Oess S. NOSTRIN: a protein modulating nitric oxide release and subcellular distribution of endothelial nitric oxide synthase. Proc Natl Acad Sci U S A. 2002;99:17167-72

41. Schilling K, Opitz N, Wiesenthal A, Oess S, Tikkanen R, Muller-Esterl W, et al. Translocation of endothelial nitric-oxide synthase involves a ternary complex with caveolin-1 and NOSTRIN. Mol Biol Cell. 2006;17:3870-80.

42. She BR, Liou GG, Lin-Chao S. Association of the growth-arrest-specific protein Gas7 with F-actin induces reorganization of microfilaments and promotes membrane outgrowth. Exp Cell Res. 2002;273:34-44.

43. You JJ, Lin-Chao S. Gas7 functions with N-WASP to regulate the neurite outgrowth of hippocampal neurons. J Biol Chem. 2010;285:11652-66.

44. Faille D, El-Assaad F, Mitchell AJ, Alessi MC, Chimini G, Fusai T, et al. Endocytosis and intracellular processing of platelet microparticles by brain endothelial cells. J Cell Mol Med. 2012;16:1731-8.

45. Tian T, Zhu YL, Zhou YY, Liang GF, Wang YY, Hu FH, et al. Exosome uptake through clathrin-mediated endocytosis and macropinocytosis and mediating miR-21 delivery. J Biol Chem. 2014;289:22258-67. 
46. Mathivanan S, Ji H, Simpson RJ. Exosomes: extracellular organelles important in intercellular communication. J Proteomics. 2010;73:1907-20.

47. Burgdorf S, Kurts C. Endocytosis mechanisms and the cell biology of antigen presentation. Curr Opin Immunol. 2008:20:89-95.

48. Schwarz LA, Patrick GN. Ubiquitin-dependent endocytosis, trafficking and turnover of neuronal membrane proteins. Mol Cell Neurosci. 2012:49:387-93.

49. Hart SP, Smith JR, Dransfield I. Phagocytosis of opsonized apoptotic cells: roles for 'old-fashioned' receptors for antibody and complement. Clin Exp Immunol. 2004;135:181-5.

50. Heinecke JW, Suits AG, Aviram M, Chait A. Phagocytosis of lipase-aggregated low density lipoprotein promotes macrophage foam cell formation. Sequential morphological and biochemical events. Arterioscler Thromb. 1991;11:1643-51.

51. Savina A, Amigorena S. Phagocytosis and antigen presentation in dendritic cells. Immunol Rev. 2007;219:143-56.

52. Takaba H, Imai T, Miki S, Morishita Y, Miyashita A, Ishikawa N, et al. A major allogenic leukocyte antigen in the agnathan hagfish. Sci Rep. 2013;3:1716.

53. Machesky LM. Lamellipodia and filopodia in metastasis and invasion. FEBS Lett. 2008;582:2102-11.

54. Luster $A D$, Alon R, von Andrian UH. Immune cell migration in inflammation: present and future therapeutic targets. Nat Immunol. 2005;6:1182-90.

55. Christie KJ, Turnley AM. Regulation of endogenous neural stem/progenitor cells for neural repair-factors that promote neurogenesis and gliogenesis in the normal and damaged brain. Front Cell Neurosci. 2012;6:70.

56. Pitchford SC, Furze RC, Jones CP, Wengner AM, Rankin SM. Differential mobilization of subsets of progenitor cells from the bone marrow. Cell Stem Cell. 2009;4:62-72.

57. De Meyer GR, Bult H. Mechanisms of neointima formation-lessons from experimental models. Vasc Med. 1997;2:179-89.

58. Siemerink MJ, Klaassen I, Van Noorden CJ, Schlingemann RO. Endothelial tip cells in ocular angiogenesis: potential target for anti-angiogenesis therapy. J Histochem Cytochem. 2013;61:101-15.

59. De Smet F, Segura I, De Bock K, Hohensinner PJ, Carmeliet P. Mechanisms of vessel branching: filopodia on endothelial tip cells lead the way. Arterioscler Thromb Vasc Biol. 2009;29:639-49.

60. Defilippi P, Olivo C, Venturino M, Dolce L, Silengo L, Tarone G. Actin cytoskeleton organization in response to integrin-mediated adhesion. Microsc Res Tech. 1999;47:67-78.

61. Starnes TW, Bennin DA, Bing X, Eickhoff JC, Grahf DC, Bellak JM, et al. The F-BAR protein PSTPIP1 controls extracellular matrix degradation and filopodia formation in macrophages. Blood. 2014;123:2703-14.

62. Guillotin B, Guillemot F. Cell patterning technologies for organotypic tissue fabrication. Trends Biotechnol. 2011;29:183-90.

63. Tsatsanis C, Spandidos DA. The role of oncogenic kinases in human cancer (review). Int J Mol Med. 2000;5:583-90.

64. Sellati TJ, Burns MJ, Ficazzola MA, Furie MB. Borrelia burgdorferi upregulates expression of adhesion molecules on endothelial cells and promotes transendothelial migration of neutrophils in vitro. Infect Immun. 1995;63:4439-47.

65. Yan S, Lv Z, Winterhoff M, Wenzl C, Zobel T, Faix J, et al. The F-BAR protein Cip4/Toca-1 antagonizes the formin Diaphanous in membrane stabilization and compartmentalization. J Cell Sci. 2013;126:1796-805.

66. Edeling MA, Sanker S, Shima T, Umasankar PK, Honing S, Kim HY, et al. Structural requirements for PACSIN/Syndapin operation during zebrafish embryonic notochord development. PLoS One. 2009;4, e8150.

67. Umasankar PK, Sanker S, Thieman JR, Chakraborty S, Wendland B, Tsang M, et al. Distinct and separable activities of the endocytic clathrin-coat components Fcho1/2 and AP-2 in developmental patterning. Nat Cell Biol. 2012;14:488-501.

68. Kovacevic I, Hu J, Siehoff-Icking A, Opitz N, Griffin A, Perkins AC, et al. The F-BAR protein NOSTRIN participates in FGF signal transduction and vascular development. EMBO J. 2012;31:3309-22.

69. Wilson NK, Lee $Y$, Long R, Hermetz K, Rudd MK, Miller R, et al. A novel microduplication in the neurodevelopmental gene SRGAP3 that segregates with psychotic illness in the family of a COS proband. Case Rep Genet. 2011;2011:585893.

70. Waltereit R, Leimer U. von Bohlen Und Halbach O, Panke J, Holter SM, Garrett $L$, et al. Srgap3(-)/(-) mice present a neurodevelopmental disorder with schizophrenia-related intermediate phenotypes. FASEB J. 2012;26:4418-28.

71. Charrier C, Joshi K, Coutinho-Budd J, Kim JE, Lambert N, de Marchena J, et al. Inhibition of SRGAP2 function by its human-specific paralogs induces neoteny during spine maturation. Cell. 2012;149:923-35.

72. Endris V, Wogatzky B, Leimer U, Bartsch D, Zatyka M, Latif F, et al. The novel Rho-GTPase activating gene MEGAP/ srGAP3 has a putative role in severe mental retardation. Proc Natl Acad Sci U S A. 2002;99:11754-9.
73. Shuib S, McMullan D, Rattenberry E, Barber RM, Rahman F, Zatyka M, et al. Microarray based analysis of 3p25-p26 deletions (3p- syndrome). Am J Med Genet A. 2009;149A:2099-105.

74. Holbert S, Dedeoglu A, Humbert S, Saudou F, Ferrante RJ, Neri C. Cdc42-interacting protein 4 binds to huntingtin: neuropathologic and biological evidence for a role in Huntington's disease. Proc Natl Acad Sci U S A. 2003;100:2712-7.

75. Marco S, Giralt A, Petrovic MM, Pouladi MA, Martinez-Turrillas R, MartinezHernandez J, et al. Suppressing aberrant GluN3A expression rescues synaptic and behavioral impairments in Huntington's disease models. Nat Med. 2013;19:1030-8.

76. Koch D, Spiwoks-Becker I, Sabanov V, Sinning A, Dugladze T, Stellmacher A, et al. Proper synaptic vesicle formation and neuronal network activity critically rely on syndapin I. EMBO J. 2011;30:4955-69.

77. Chen Y, Aardema J, Kale S, Whichard ZL, Awomolo A, Blanchard E, et al. Loss of the F-BAR protein CIP4 reduces platelet production by impairing membrane-cytoskeleton remodeling. Blood. 2013;122:1695-706.

78. Smith EJ, Allantaz F, Bennett L, Zhang D, Gao X, Wood G, et al. Clinical, molecular, and genetic characteristics of PAPA syndrome: a review. Curr Genomics. 2010;11:519-27.

79. Ferguson PJ, Bing X, Vasef MA, Ochoa LA, Mahgoub A, Waldschmidt TJ, et al. A missense mutation in pstpip2 is associated with the murine autoinflammatory disorder chronic multifocal osteomyelitis. Bone. 2006;38:41-7.

80. Cassel SL, Janczy JR, Bing X, Wilson SP, Olivier AK, Otero JE, et al. Inflammasome-independent IL-1 beta mediates autoinflammatory disease in Pstpip2-deficient mice. Proc Natl Acad Sci U S A. 2014;111:1072-7.

81. Yamamoto H, Sutoh M, Hatakeyama S, Hashimoto Y, Yoneyama T, Koie T, et al. Requirement for FBP17 in invadopodia formation by invasive bladder tumor cells. J Urol. 2011;185:1930-8.

82. Hu J, Mukhopadhyay A, Truesdell P, Chander H, Mukhopadhyay UK, Mak AS, et al. Cdc42-interacting protein 4 is a Src substrate that regulates invadopodia and invasiveness of breast tumors by promoting MT1-MMP endocytosis. J Cell Sci. 2011;124:1739-51.

83. Fuchs U, Rehkamp G, Haas OA, Slany R, Konig M, Bojesen S, et al. The human formin-binding protein 17 (FBP17) interacts with sorting nexin SNX2, and is an MLL-fusion partner in acute myelogeneous leukemia. Proc Natl Acad Sci U S A. 2001;98:8756-61.

84. Craig AW. FES/FER kinase signaling in hematopoietic cells and leukemias. Front Biosci (Landmark Ed). 2012;17:861-75.

85. Han Y, Cui J, Lu Y, Sue S, Arpaia E, Mak TW, et al. FCHSD2 predicts response to chemotherapy in acute myeloid leukemia patients. Leuk Res. 2012;36:1339-46.

86. Rusconi F, Thakur H, Li J, Kapiloff MS. CIP4 is required for the hypertrophic growth of neonatal cardiac myocytes. J Biomed Sci. 2013;20:56.

87. Hartig SM, Ishikura S, Hicklen RS, Feng Y, Blanchard EG, Voelker KA, et al. The F-BAR protein CIP4 promotes GLUT4 endocytosis through bidirectional interactions with N-WASp and Dynamin-2. J Cell Sci. 2009;122:2283-91.

88. Roach W, Plomann M. PACSIN3 overexpression increases adipocyte glucose transport through GLUT1. Biochem Biophys Res Commun. 2007;355:745-50.

89. Bai S, Zeng R, Zhou Q, Liao W, Zhang Y, Xu C, et al. Cdc42-interacting protein-4 promotes TGF-Beta1-induced epithelial-mesenchymal transition and extracellular matrix deposition in renal proximal tubular epithelial cells. Int J Biol Sci. 2012:8:859-69.

\section{Submit your next manuscript to BioMed Central and take full advantage of:}

- Convenient online submission

- Thorough peer review

- No space constraints or color figure charges

- Immediate publication on acceptance

- Inclusion in PubMed, CAS, Scopus and Google Scholar

- Research which is freely available for redistribution 